\title{
GENETIC DIVERSITY OF RICE BLAST FUNGUS POPULATIONS (Pyricularia grisea) USING MOLECULAR MARKERS
} El-Wahsh S.M. ' ; Y.Z. El-Refaee ${ }^{2}$; A. A. Emeran'; S. F. Mashaal ${ }^{3}$ and R. A. Arafa ${ }^{1}$

${ }^{1}$ Rice Pathology Dept., Plant Pathology Res. Inst. , Agri. Res. Center.

${ }^{2}$ Rice Research and Training Center,Field Crops Res. Inst., Agri. Res. Center, ${ }^{3}$ Dept. of Agric. Botany, Faculty of Agriculture, Kafrelsheikh University, 33516 Kafrelsheikh, Egypt

\begin{abstract}
Pyricularia grisea fungus which causing rice blast disease is one of the main pathological races threats to rice crop in Egypt and worldwide. Thirty isolates out of known 144 strains of this fungus were selected according to geographical locations. Isolates of $P$. grisea, were analyzed by SSR markers to determine the amount of genetic variability among these races. Sixteen primers out of 26 were amplified and produced a total of 83 alleles . Number of alleles per marker ranged from 3 for C7-1.4, P90.4 and P9-1.9 to 9 for H6-0.8-5 primer, with an average of 5.2. The polymorphic information content (PIC) values were high for all markers with an average of 0.70 and ranged from as low as 0.51 for C7-1. 4 to high of 0.83 for H6-0.8-5 marker. UPGMAcluster-analysis based on genetic distance coefficients clearly separated all isolates of P. grisea. The results showed that the studied isolates were classified into 4 lineages by cutting off the dendrogram at 0.70 similar linkage level. Group D was the major group and represented most of those isolates. The average similarities within cluster was greater than the average similarities between clusters. In general, the results of this investigation confirmed that microsatellite markers would be useful and suitable for determining the genetic diversity in $P$. grisea populations.
\end{abstract}

Keywords: rice blast, genetic diversity, Pyricularia grisea, PCR, SSR.

\section{INTRODUCTION}

Rice blast disease caused by Pyricularia grisea is one of the most important rice diseases which attack rice throughout its life cycle from the nursery to the farm [Ou 1985] in all rice countries including Egypt. Therefore, many studies were done to control it [Khodaparast and Sahragard 2004]. DNA markers show the differences of DNA. These markers were used because of being unlimited in numbers, not being affected by environmental factors and furthermore their detection and identification throughout their plant growth processes [Winter and Khal 1995]. The genetic diversity range and instability in Pyricularia grisea has been the long-term discussion among the blast studies. The application of the molecular markers in the genetic study of the population presented classification of the epidemiologic information which was not possible before. Molecular marker would detect the genetic contents directly and they could validly refer to genetic and phenotypic variations [Babujee and Gnanamanickam 2000]. Liu et al. [2008] evaluated 46 isolates of rice blast fungus that obtained from different geographical areas in order to determine its DNA configuration by the use of SSR markers. The first results indicated that each locus had a range of different alleles from 2 to 10 and the results of SSR showed genes which were polymorphic in nature [Liu et al. 2008]. Silva et al. [2009] evaluated the genetic diversity of $P$. grisea on rice in Brazil. The genetic analysis of isolates showed the highest genetic diversity population belonged to 103 haplotypes in Bonanca and 49 in Primavera. Mottalebi et al. [2009] examined $P$. grisea populations isolated from rice and weeds and analyzed the genetic variability of complex species of this fungus by Rep-PCR and concluded that genetic diversity in these isolates is low. Piotti et al. [2005] determined the genetic structures of isolates of $P$. grisea in Italy and fingerprinted the DNA of the pathogen using the PCR. The cluster analysis showed the existence of three Italian main genetic groups which had $80 \%$ similarities. The goal of this study was to determined the phenotypic and genetic variability of the selected races of $P$. grisea by using SSR based on the PCR as well as the similarities among these races. In other study, fingerprinting of eleven isolates of $P$. oryzae by retrotransposon - microsatellite amplified polymorphism (REMAP) showed a high level of polymorphism and variability among them. Phylogenetic analysis using REMAP markers separated one rice isolate from others [Vanaraj et al. 2013] . Random amplified polymorphic DNA markers were used to find out genetic variability in $P$. grisea isolates that obtained from farmer's fields in Northeast India. 28S rRNA gene sequences of the isolates were compared with other related taxa retrieved from Gene Bank database. The results confirmed the genetic variability of rice blast fungus in Northeast India [Gad et al. 2013]. Motlagh et al. [2015] studied the genetic and molecular characterization of $P$. grisea by using SSR markers based on the PCR in Guilan province of Iran. They determined the similarities as well as the genetic differences among the studied populations. The results showed that genetic distance was large between isolates of west and east of Guilan and the genetic similarity among these isolates of the two populations was low. However, there was a maximum of genetic distance or a minimum of genetic similarity among the populations of center and east of Guilan isolates.

In this study, the genetic and molecular characterization of $P$. grisea races were determined using SSR markers based on the PCR in six rice growing governorates in Egypt and the similarities as well as the genetic differences among these races were determined. 


\section{MATERIALS AND METHODES}

The present study was carried out in both the experimental farm and the green house of the Rice Research and Training center (RRTC), Rice Pathology Department, Sakha, Kafr El- Sheikh, Egypt and Department of Agric. Botany, Faculty of Agriculture, Kafr el-sheikh University during the period from 2008 to 2012.

\section{Fungus isolates selection:}

Thirty isolates out of known144 isolates of Pyricularia grisea fungus were selected according to geographical location, physiological races and seasons . Each isolate was grown for 15 days at room temperature (25 to $27^{\circ} \mathrm{C}$ ) in $100 \mathrm{ml}$ of potato dextrose broth. The mycelia harvested by filtration with air bump.

\section{Microsatellite marker analysis:}

Total genomic DNA was extracted from fresh fungus mycelia about $0.5 \mathrm{~g}$ from each isolate using CTAB (Cetyl-tetramethyl ammonium bromide) method,
(Murray and Thompson, 1980). Purity and concentration of DNA was monitored spectrophotometrically at a wavelength of 260 and 280 $\mathrm{nm}$ using Nano-Drop ND-1000 Spectrophotometer (Wilmington, USA). The thirty isolates used initially were subjected to DNA polymorphism screening using 26 SSR markers. Sixteen markers out of those 26 (Table 1) were amplified and used to determine the genetic diversity and molecular characterisation of Pyricularia grisea populations. PCR amplifications were performed in a $20 \mu \mathrm{l}$ reaction volume: each reaction contained 1.0 $\mu 1$ template DNA; $0.10 \mu$ l Taq polymerase, $4 \mu 1$ of $10 \mathrm{X}$ buffer, $1 \mu 1$ of $10 \mathrm{mM}$ of each of the four (dNTPs), $1.0 \mu 1$ of $10 \mathrm{mM}$ forward and reverse primers. The volume was brought up to $20 \mu \mathrm{l}$ by autoclaved double distilled $\mathrm{H} 2 \mathrm{O}$. The amplification protocol of $5 \mathrm{~min}$ at $94{ }^{\circ} \mathrm{C}, 35$ cycles, each cycle performed with $40 \mathrm{sec}$ at $94^{\circ} \mathrm{C} ; 40 \mathrm{sec}$ at lower annealing temperature of the primer about 50 up to $68{ }^{\circ} \mathrm{C} ; 1 \mathrm{~min}$ at $72{ }^{\circ} \mathrm{C}$, and a final extension step of $10 \mathrm{~min}$ at $72^{\circ} \mathrm{C}$.

Table 1: List of SSR primer used for molecular analysis.

\begin{tabular}{lccc}
\hline No. & Name marker & F. marker sequences & R. marker sequences \\
\hline 1 & C7-1.4 & TGCCGCCTGCTCTAAGTAAA & TATCCTTCACCAACGACACC \\
2 & CUT1 & TATAGCGTTGACCTTGTGGA & TAAGCATCTCAGACCGAACC \\
3 & E10 & ACCAGGTGACGTCGATAAGC & CTGACGCCAAAAGCAAGTTA \\
4 & ERG2 & GCAGGGCTCATTCTTTTCTA & CCGACTGGAAGGTTTCTTTA \\
5 & H6-0.8-4 & GGACAAGCAAGACAAGGTAT & CGACAAAGCAGAGAAAGAGG \\
6 & H6-0.8-5 & CATCTACAACCCGAGCAAGG & TGTAAAACAGCCCATCAAAG \\
7 & H6-1.1-5 & TGTATGATGCGAGCGGACTT & TGGACTGGGTATTGTTGAGC \\
8 & H6-1.1-7 & AGTGGTGGATACGAGCAGGG & AGGAAACACAAAGCGAGGAT \\
9 & J13-1.4 & CCTAACCAGTTCCTCCGTAT & TATGCTCCCCATTTTTAT TA \\
10 & J16-0. & GTTAGGGCTACAGGCGGAAG & CTGTGGCGACGATCTGTGGT \\
11 & J16-0.9 & TTGACTGTATTGTTGCCGTT & GGGCGACAGGTTGAAGAGTT \\
12 & P9-0.4 & CGGCAAATACTTCCACCATA & GGTCCTTCGTTGAGCAGATA \\
13 & P9-1.9 & ACCCCACTCGCTGACCTTTA & CGGACGCTTGATTGCTGTTA \\
14 & PWL2 & TCCGCCACTTTTCTCATTCC & GCCCTCTTCTCGCTGTTCAC \\
15 & S9 & TCTGAAAGCCGTCCCCACAT & ACACCCCTCCAAAACCACAA \\
16 & Y16 & ATTTAGAAGGCAGGGGTGTC & TGTGTGAAAACAAGGCAAGC \\
\hline
\end{tabular}

\section{Allele scoring and data analysis:}

Ethidium bromide staining of agarose gels generally showed several bands. The size of the most intensively amplified band for each microsatellite marker was determined based on its electrophoretic mobility relative to molecular weight markers (increments of $50 \mathrm{bp}$ ). Amplified products from SSR analysis were scored qualitatively for presence and absence of each marker allele-isolate combination. Each SSR band amplified by a given primer was treated as a unit character. Data was entered into a binary matrix as discrete variables, 1 for presence and 0 for absence of the character. The most informative markers were selected based on the extent of polymorphism. The polymorphic information content (PIC) value of a marker was calculated according to Anderson et al., (1993). Mean allele numbers, PIC values, and genetic similarities were calculated on the basis of different rice genotypes and microsatellite classes. Genetic similarities between all pair of the isolates were calculated according to Nei and Li (1979). A cluster diagram was constructed based on these distances by the UPGMA (average linkage) method to develop a dendogram. The similarity matrix, genetic distances and dendogram analysis were computed using Numerical Taxonomy and Multivariate Analysis system, Version 2.1(Rolhf, 2000 NTSYSpc).

\section{RESULTS AND DISCUSSIONS}

Thirty isolates were selected according to geographical location, physiological races and seasons as presented in Table 2. Nucleic acid i.e. the DNA of these isolates were extracted and subjected to 26 specific primers for Pyricularia grisea fungus. The molecular markers were selected from those in Table 1 to determine the genetic diversity and molecular characterization of Pyricularia grisea populations.

The results showed that the most common race groups were ID which represented $31.95 \%$ from the total races followed by IH and IG race groups. These common race groups represent all main rice growing 
governorates except Damietta governorate. While IC race group appeared in Kafrelsheikh, Beheira and Gharbia isolates, IB race group from Kafrelsheikh, Dakahlia, Beheira and Gharbia, II race group from Kafrelsheikh, Sharkia, Dakahlia and Damietta, IF race group from only Kafrelsheikh. Also, IA and IE race groups were collected from only Kafrelsheikh governorate. This may indicate that the existence of new pathotype (s) in some locations raises the inoculums levels in these areas, and enhance the frequency pathotypes. These results are in agreement with the findings of Sehly et al. (2002) who reported that the distribution of physiological blast races varied among rice growing governorates. The common physiological races (pathotypes) suggest the existence of a wide genetic variability of blast races in Egypt. The genetic variability of the rice pathogen $P$. grisea in Egypt, in the northern half of the Nile Delta, especially, the six northern governorates namely; Dakahlia, Kafrelsheikh, Beheira, Sharkia, Gharbia and Damietta which altogether share about $98 \%$ of the total rice acreage (Badawi et al. 2002).

Table 2: Physiological blast races with its collecting locations which used to simple sequence repeats technique.

\begin{tabular}{|c|c|c|c|c|c|}
\hline Serial No. & Isolate No. & Location & Variety & Race & Year \\
\hline 1 & 17 & Kafrelsheikh & S.101 & IE-7 & 2008 \\
\hline 2 & 38 & Kafrelsheikh & S.101 & IF-3 & 2008 \\
\hline 3 & 13 & Kafrelsheikh & IRTP21662 & II-1 & 2008 \\
\hline 4 & 43 & Kafrelsheikh & Giza 159 & IG-1 & 2008 \\
\hline 5 & 56 & Kafrelsheikh & S.101 & IC-13 & 2009 \\
\hline 6 & 60 & Kafrelsheikh & $\mathrm{H} 2$ & IH-1 & 2009 \\
\hline 7 & 76 & Kafrelsheikh & S.104 & IA-41 & 2009 \\
\hline 8 & 91 & Kafrelsheikh & Reiho & ID-5 & 2009 \\
\hline 9 & 125 & Kafrelsheikh & IR70554-48-1-2 & IB-33 & 2010 \\
\hline 10 & 2 & Behera & S.101 & IC-31 & 2008 \\
\hline 11 & 19 & Behera & G.171 & IG-1 & 2008 \\
\hline 12 & 85 & Behera & S.101 & IH-1 & 2009 \\
\hline 13 & 119 & Behera & S.101 & ID-13 & 2010 \\
\hline 14 & 121 & Behera & Pi No.4 & IB-41 & 2010 \\
\hline 15 & 28 & Sharkia & S.101 & II-1 & 2008 \\
\hline 16 & 68 & Sharkia & S.101 & IG-1 & 2009 \\
\hline 17 & 102 & Sharkia & Pi No.4 & IH-1 & 2009 \\
\hline 18 & 114 & Sharkia & G.171 & ID-13 & 2010 \\
\hline 19 & 26 & Damietta & S.101 & II-1 & 2008 \\
\hline 20 & 88 & Damietta & Dinebra retroflexa & II-1 & 2009 \\
\hline 21 & 21 & Dakahlia & S.101 & II-1 & 2008 \\
\hline 22 & 25 & Dakahlia & S.101 & IB-61 & 2008 \\
\hline 23 & 27 & Dakahlia & S. 101 & IH-1 & 2008 \\
\hline 24 & 78 & Dakahlia & S.101 & IG-1 & 2009 \\
\hline 25 & 122 & Dakahlia & S.101 & ID-13 & 2010 \\
\hline 26 & 53 & Gharbia & S.101 & ID-9 & 2009 \\
\hline 27 & 62 & Gharbia & S.101 & IG-1 & 2009 \\
\hline 28 & 63 & Gharbia & S.101 & IH-1 & 2009 \\
\hline 29 & 87 & Gharbia & S.104 & IB-29 & 2009 \\
\hline 30 & 92 & Gharbia & S. 101 & IC-13 & 2009 \\
\hline
\end{tabular}

In this investigation, the isolates were expected to be representative of the Egyptian fungal races due to some reasons i.e., (i) this region is the site where the different rice varieties were cultivated for a long term about over the last 100 years; (ii) blast symptoms have been observed in this region on the susceptible cultivars throughout the years, thus creating a continuous source of inoculums and (iii) Pyricularia grisea has a wide host range, where it parasitizes more than 50 other species of grasses and sedges, many of which are common weeds in rice fields $(\mathrm{Ou}, 1985)$. Fifteen weed isolates obtained from different rice growing governorates during 2009 and 2010 were identified as 4 races in Egypt as IG1 (6.6\%), IB (26.7\%) and ID (6.7\%), Sehly et at (2009). They found that the rice isolates were able to infect old and new commercial rice cultivars. While, the weed isolates infected only the old commercial rice cultivars. In a similar condition, Brondani et al. (2000) found a striking complex genetic structure in the $P$. grisea population sampled in the year 2000 in a Brazilian area (1.0 ha). The thirty isolates used initially were subjected to DNA polymorphism screening using 26 SSR markers. Sixteen markers out of those 26 were amplified and showed high polymorphism with all tested isolates. SSR markers were used to determine the genetic diversity and molecular characterization of Pyricularia grisea populations. Figures 1,2 and 3 illustrated the come out results from three primers out of 16 primers that used in this study and showed high level of polymorphism through all the tested isolates. 


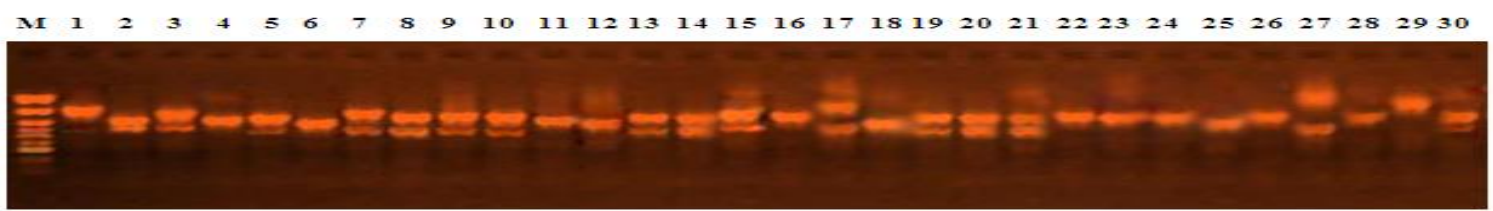

Fig. (1): Polymorphism survey of 30 races using SSR markers, the primers shown is $(\mathrm{C7}-1.4)$ and $\mathrm{M}$ is 1500 bp ladder, where:

\begin{tabular}{|c|c|c|c|c|c|c|c|c|c|}
\hline Lane1: & 17- IE-7 & Lane 7: & 76-IA-41 & Lane13 : & 119-ID-13 & Lane19: & 26-II-1 & Lane25: & 122-ID-13 \\
\hline ane 2: & 38-IF-3 & Lane 8: & 91-ID-5 & Lane 14: & 121-IB-41 & Lane20: & 88-II-1 & Lane26: & 53-ID-9 \\
\hline ane 3: & 13-II-1 & Lane 9: & 125-IB-33 & Lane 15: & 28-II-1 & Lane21: & 21-II-1 & Lane27: & 62-IG-1 \\
\hline ane 4: & 43-IG-1 & Lane 10: & 2-1C-31 & Lane 16: & 68-IG-1 & Lane22: & 25-IB-61 & Lane28: & 63-IH-1 \\
\hline ane 5: & 56-IC-13 & Lane 11: & 19-IG-1 & Lane 17: & 102-IH-1 & Lane23: & 27-IH-1 & Lane29: & 87-IB-29 \\
\hline Lane 6: & 60-IH-1 & Lane 12: & 85-IH-1 & Lane 18: & 114-ID-13 & Lane24: & 78-IG-1 & Lane30: & 92-IC-13 \\
\hline
\end{tabular}

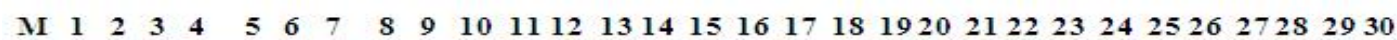

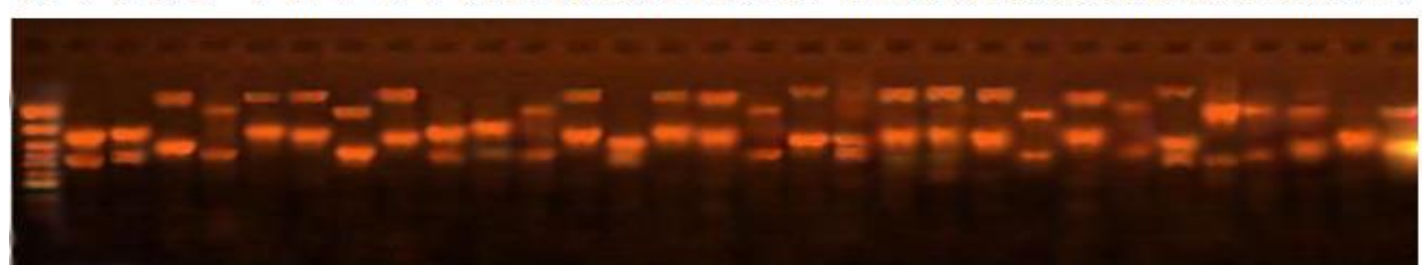

Fig. (2): Polymorphism survey of 30 races using SSR markers, the primers shown is (CUT 1) and $M$ is 1500 bp ladder, where:

\begin{tabular}{|c|c|c|c|c|c|c|c|c|c|}
\hline 1 : & 17- IE-7 & Lane 7: & 76-IA-41 & Lane13 : & 119-ID-13 & Lane19: & 26-II-1 & Lane25: & 122-ID \\
\hline Lane 2: & 38-IF-3 & Lane 8: & 91-ID-5 & Lane 14: & 121-IB-41 & Lane20: & 88-II-1 & Lane26: & 53-ID- \\
\hline Lane 3: & 13-II-1 & Lane 9: & 125-IB-33 & Lane 15: & 28-II-1 & Lane21: & 21-II-1 & Lane27: & 62-IG-1 \\
\hline Lane 4: & 43-IG-1 & Lane 10: & $2-1 C-31$ & Lane 16: & 68-IG-1 & Lane22: & 25-IB-61 & Lane28: & 63-IH- \\
\hline Lane 5: & 56-IC-13 & Lane 11: & 19-IG-1 & Lane 17: & 102-IH-1 & Lane23: & 27-IH-1 & Lane29: & 87-IB-2 \\
\hline Lane 6: & 60-IH-1 & Lane 12: & 85-IH-1 & Lane 18: & 114-ID-13 & Lane24: & 78-IG-1 & Lane30: & 92-IC-1 \\
\hline
\end{tabular}

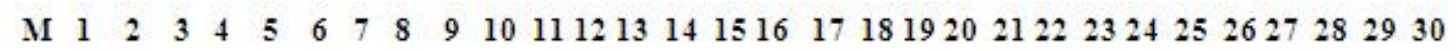

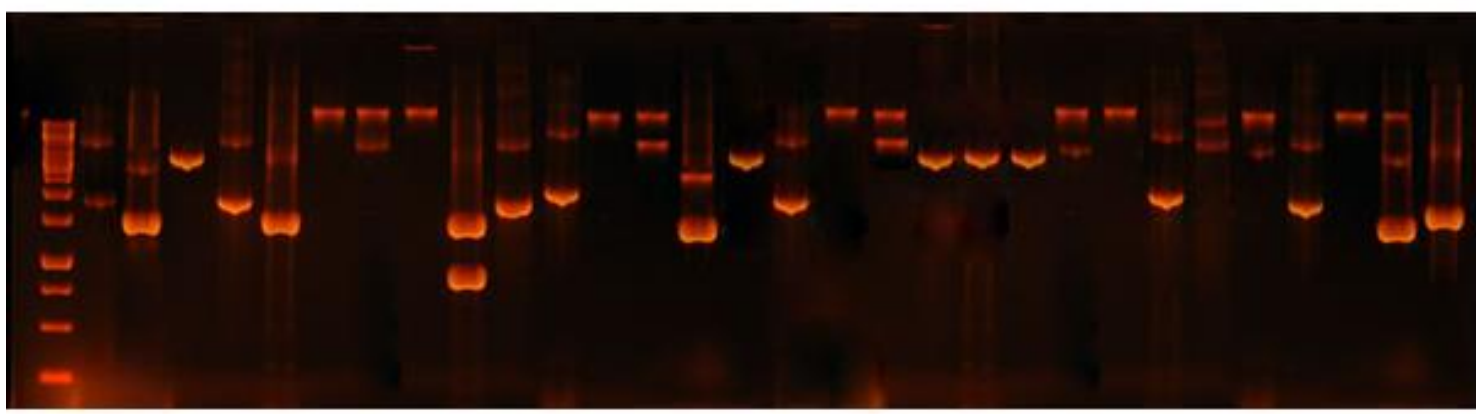

Fig. (3): Polymorphism survey of 30 races using SSR markers, the primers shown is (E 10) and $M$ is $1500 \mathrm{bp}$ ladder, where:

\begin{tabular}{|c|c|c|c|c|c|c|c|c|c|}
\hline Lane1 : & 17- IE-7 & Lane 7: & 76-IA-41 & Lane13 : & 119-ID-13 & Lane19: & 26-II-1 & Lane25: & 122-ID-13 \\
\hline Lane 2: & 38-IF-3 & Lane 8: & 91-ID-5 & Lane 14: & 121-IB-41 & Lane20: & 88-II-1 & Lane26: & 53-ID-9 \\
\hline Lane 3: & 13-II-1 & Lane 9: & 125-IB-33 & Lane 15: & 28-II-1 & Lane21: & 21-II-1 & Lane27: & 62-IG-1 \\
\hline Lane 4: & 43-IG-1 & Lane 10: & $2-1 C-31$ & Lane 16: & 68-IG-1 & Lane22: & 25-IB-61 & Lane28: & 63-IH-1 \\
\hline Lane 5 & 56-IC-13 & Lane 11: & 19-IG-1 & Lane 17: & 102-IH-1 & Lane23: & 27-IH-1 & Lane29: & 87-IB-29 \\
\hline Lane 6: & 60-IH-1 & Lane 12: & 85-IH-1 & Lane 18: & 114-ID-13 & Lane24: & 78-IG-1 & Lane30: & 92-IC-1 \\
\hline
\end{tabular}

The simple sequence repeat markers (SSR) is considered as a useful tool for diversity assessment due to their high level of polymorphism (McCouch et al. 2002).

In this investigate 83 polymorphic fragments were generated. Sizes of bands were floating between 180-950 bp. The largest base pair was generated by C7-
1.4 primer and the smallest by the P9-1.9 primer. The most generated bands were amplified at the time of application of primer H6-0.8-5 and the least generated bands were amplified with application of primers (C71.4, P9-0.4 and P9-1.9), respectively. The average of generation was 5.2 bands for each of the primers (tab. 3). All the generated bands were polymorphic 
Table 3. Number of bands and amplified band size by each marker.

\begin{tabular}{|c|c|c|c|c|c|c|c|c|c|c|c|c|}
\hline \multirow[b]{2}{*}{ Name of marker } & \multirow{2}{*}{$\begin{array}{l}\text { No. of alleles in } \\
\text { each marker }\end{array}$} & \multicolumn{10}{|c|}{ Number of strains possessing each of alleles } & \multirow{2}{*}{$\begin{array}{l}\text { Bands size } \\
\quad \text { (bp) }\end{array}$} \\
\hline & & $\begin{array}{l}\text { Non- } \\
\text { bands }\end{array}$ & $\mathbf{1}$ & 2 & 3 & 4 & 5 & 6 & 7 & 8 & 9 & \\
\hline$\overline{\mathrm{C}} 7-1.4$ & 3 & - & 6 & 13 & 11 & & & & & & & $850-950$ \\
\hline CUT1 & 7 & - & 10 & 5 & 5 & 12 & 8 & 7 & 6 & & & $770-950$ \\
\hline E10 & 6 & 3 & 1 & 4 & 7 & 3 & 9 & 12 & & & & $250-950$ \\
\hline ERG2 & 5 & - & 6 & 5 & 23 & 6 & 11 & & & & & $400-900$ \\
\hline H6-0.8-4 & 7 & - & 2 & 7 & 15 & 5 & 15 & 7 & 8 & & & $340-900$ \\
\hline H6-0.8-5 & 9 & - & 1 & 12 & 7 & 14 & 9 & 8 & 21 & 7 & 5 & $320-900$ \\
\hline H6-1.1-5 & 5 & 2 & 7 & 8 & 19 & 15 & 3 & & & & & $250-900$ \\
\hline H6-1.1-7 & 4 & - & 5 & 15 & 28 & 4 & & & & & & $230-350$ \\
\hline J13-1.4 & 5 & - & 12 & 15 & 3 & 21 & 13 & & & & & $350-700$ \\
\hline J16-0. & 5 & 2 & 2 & 4 & 14 & 11 & 18 & & & & & $300-700$ \\
\hline J16-0.9 & 4 & 2 & 2 & 17 & 13 & 3 & & & & & & $200-400$ \\
\hline P9-0.4 & 3 & - & 16 & 17 & 17 & & & & & & & $700-800$ \\
\hline P9-1.9 & 3 & - & 6 & 10 & 29 & & & & & & & $180-400$ \\
\hline PWL2 & 5 & - & 13 & 14 & 3 & 22 & 5 & & & & & $550-900$ \\
\hline S9 & 8 & - & 10 & 12 & 5 & 13 & 15 & 12 & 10 & 10 & & $500-950$ \\
\hline Y16 & 4 & 1 & 1 & 10 & 18 & 22 & & & & & & $400-700$ \\
\hline
\end{tabular}

To study the primers efficiency and to determine the surface of polymorphism, the polymorphism information content (PIC), Nei's genetic diversity, observed number of alleles (na), and effective number of alleles (ne) were calculated and are presented in Table 4.

PIC was the first important index in determination of primers efficiency [Agrama and Tuinstra 2003]. The amount of PIC was the reflection of allele diversity among the isolates. The high polymorphism in microsatellites showed the high diversity and it suggested the high amount of mutation which occurred in microsatellites sequences [Zhou et al. 2003]. The observed polymorphism information (PIC) of all used primers ranged between 0.51 to 0.83 as seen in Table 4. When the number was close to 1 suggested presence of more alleles indicating polymorphism in that population which showed more uniform distribution of polymorphism bands among the isolates. The results showed that primer H6-0.8-5 with PIC $=0.83$ had the most PIC among the 16 markers, and it could show the genetic distances between isolates better than the other primers. The C7-1. 4 primer with PIC $=0.51$ showed the less PIC. The average of PIC was 0.70 for all the markers which suggested that the almost perfect choice for the primers which study the genetic diversity of the isolates in this study.

Table 4: Polymorphism information content (PIC), observed number of alleles (na), number of effective alleles (ne), Nei's index (Nei) in microsatellite sites in all the studied isolates.

\begin{tabular}{lcccc}
\hline Name of marker & PIC & na & ne & Nei \\
\hline C7-1.4 & 0.510 & 3 & 2.21 & 0.510 \\
CUT1 & 0.792 & 7 & 3.09 & 0.792 \\
E10 & 0.739 & 6 & 3.39 & 0.739 \\
ERG2 & 0.715 & 5 & 2.79 & 0.715 \\
H6-0.8-4 & 0.795 & 7 & 2.86 & 0.795 \\
H6-0.8-5 & 0.830 & 9 & 3.82 & 0.830 \\
H6-1.1-5 & 0.735 & 5 & 2.75 & 0.735 \\
H6-1.1-7 & 0.642 & 4 & 2.07 & 0.642 \\
J13-1.4 & 0.723 & 5 & 2.57 & 0.723 \\
J16-0. & 0.729 & 5 & 3.15 & 0.729 \\
J16-0.9 & 0.651 & 4 & 1.95 & 0.651 \\
P9-0.4 & 0.530 & 3 & 1.86 & 0.530 \\
P9-1.9 & 0.570 & 3 & 1.90 & 0.570 \\
PWL2 & 0.732 & 5 & 3.18 & 0.732 \\
S9 & 0.820 & 4 & 3.36 & 0.820 \\
Y16 & 0.673 & 5.2 & 2.58 & 0.673 \\
An average & 0.70 & & 2.72 & 0.70 \\
\hline
\end{tabular}

According to the results, the most Nei's genetic diversity in all isolates was observed in primer H6-0.85 and the least amount was observed in primer C7-1.4 as presented in Table 4 . The average of genetic diversity in all the primers for all isolates was 0.70 which suggested the perfect allele's diversity used in this study. All the primers used in this research were 


\section{El-Wahsh S.M.et al}

polymorphic and generated a variety of alleles with different sizes.

The maximum observed number of alleles (9 alleles) and maximum effective number of alleles (3.82) in all the isolates like the maximum of the PIC and maximum of the genetic diversity were seen by primer H6-0.8-5. This suggested that this primer in addition to producing maximum alleles it would be introduce as one of the perfect microsatellite primers for studying the genetic diversity of Pyricularia grisea where these alleles had a uniform distribution among the reviewed isolates. The minimum observed number of alleles (3) in all the isolates like the minimum of PIC and Nei's genetic diversity were seen in primer C7-1.4, but the minimum of effective number of alleles (1.86) derived from primer P9-0.4 (table 4).

Generating the different alleles by the SSR markers were reported in the previous studies by Liu et al. [2008] who found genetic variability in P. grisea using SSR markers reporting a range of 2 to 10 alleles. Motlagh et al. [2015] studied the genetic diversity of $P$. grisea by using SSR markers and found a range of 3 to 8 alleles. The number of alleles that generated by different SSR markers used in this study were in agreement with the previous studies.
Based on PIC amounts in this study, 16 used primers had suitable distribution between isolates in addition to producing the almost suitable polymorphism bands. A similar study was done on the genetic diversity of this fungus in the central regions of Brazil by SSR markers [Brondani et al. 2000]. Amount of PIC ranged from 0.44 to 0.54 for different microsatellite primers. Motlagh et al. [2015] studied the genetic diversity of $P$. grisea populations of Guilan province in Iran. They reported that the amount of PIC ranged from 0.661 to 0.862 for 14 SSR markers. The amount of PIC in this study ranged from 0.51 to 0.83 . The amount of PIC was in agreement with the previous studies.

Genotyping grouping were performed based on Numerical Taxonomy System of Multivariate Programs (NTSYS) similarity coefficients. The genetic distance matrix was utilized for cluster analysis based on UPGMA. Using sixteen SSR markers to construct phylogenetic relationships among 30 isolates of Pyricularia grisea to be classified into two main groups (A \& B) and further subdivided into six subgroups. The coefficients of similarity ranged from $67 \%$ to $100 \%$ as seen in Figure 4.

The average similarity within cluster was greater than the average similarity between the clusters.

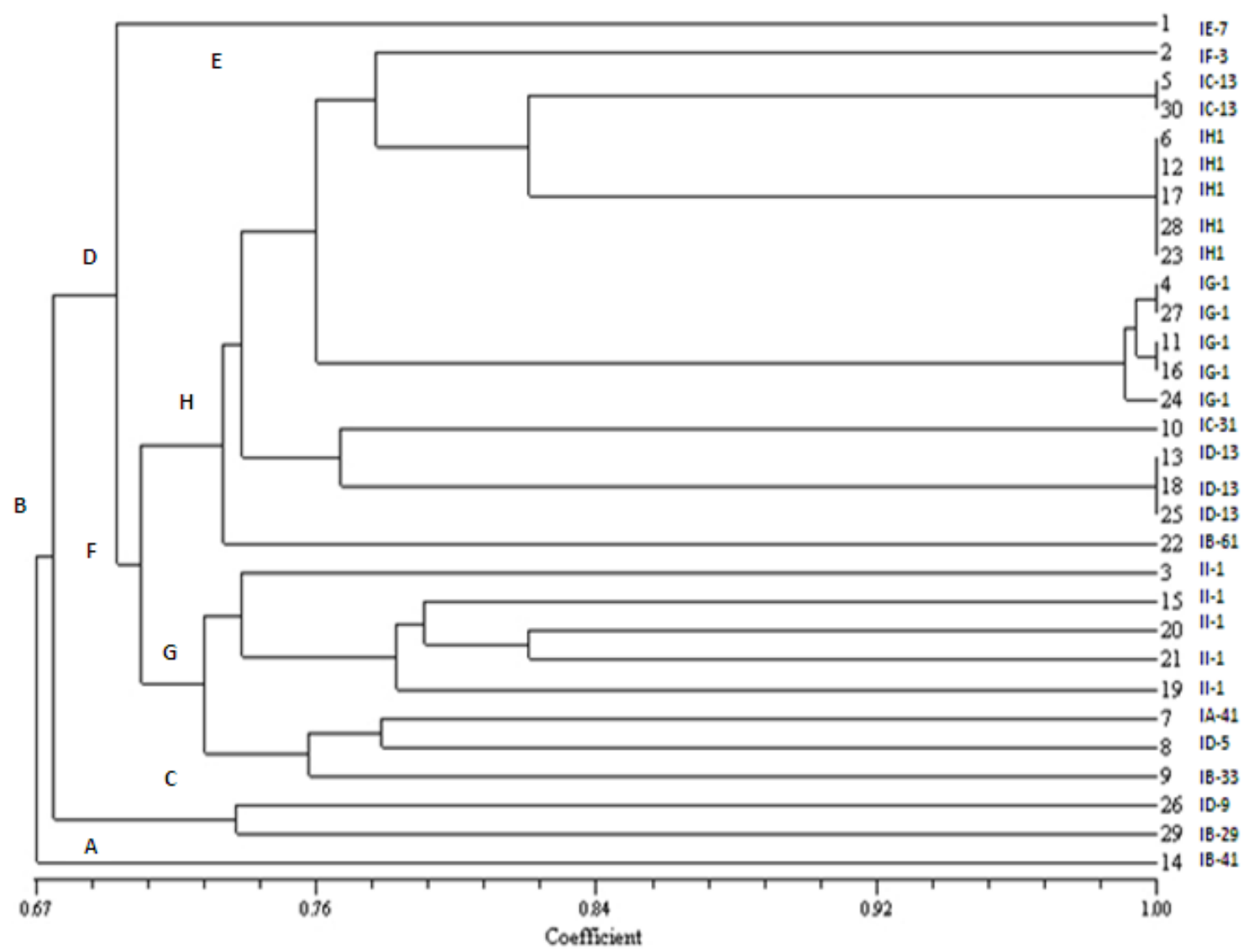

Fig. 4: Dendrogram derived from banding patterns of 30 isolates of Pyricularia grisea by UPGMA.

The first main group (A) included one isolate with number 14(121) that was identified as IB-41. The second main group (B) included the remain of 29 isolates. The second main group (B) was also divided into two subgroups (C and D). The subgroup (C) included two isolates with numbers 26 (53) and 29 (87) and were identified as ID-9 and IB-29, respectively with 
$74 \%$ similarity. The subgroup (D) consisted of 27 isolates with numbers 1 (17), 2(38), 5(56), 30(92), 6(60), 12(85), 17(102), 28(63), 23(27), 4(43), 27(62), 11(19), 16(68), 24(78), 10(2), 13(119), 18(114), 25(122), 22(25), 3(13), 15(28), 20(88), 21(21), 19(26), $7(76), 8(91)$ and $9(125)$ with $70 \%$ similarity. The second subgroup (D) was further divided into two subsubgroups (E and F). The first sub- subgroup (E) included one isolate with number 1(17) and was identified as IE-7. The sub- subgroup (F) included 26 isolates with numbers 2(38), 5(56), 30(92), 6(60), 12(85), 17(102), 28(63), 23(27), 4(43), 27(62), 11(19), 16(68), 24(78), 10(2), 13(119), 18(114), 25(122), 22(25), 3(13), 15(26), 20(88), 21(21), 19(26), 7(76), 8(91) and 9(125).

The sub- subgroup (F) included two groups (G and $\mathrm{H})$. Group $(\mathrm{G})$ consists of eight isolates with numbers 3(13), 15(26), 20(88), 21(21), 19(26), 7(76), $8(91)$ and 9(125), but group (H) included 18 isolates with numbers 2(38), 5(56), 30(92), 6(60), 12(85), 17(102), 28(63), 23(27), 4(43), 27(62), 11(19), 16(68), 24(78), 10(2), 13(119), 18(114), 25(122) and 22(25) with $75 \%$ similarity. Results in Figure (4) and Table (2) show that there are relationships between pathotype (race) and lineages (group), but there are no relationships between locations, varieties and lineages (groups). Two isolates, out of 30 isolates, namely 1(17) and 2(38) were identified as IE-7 and IF-3, respectively, with one unique group for everyone. While, isolates numbers 5(56) and 30(92) which were identified as IC13 were placed into one group with $100 \%$ similarity and were collected in the same season (2009 season). Also, isolates numbers 6(60), 12(85), 17(102), 28(63) and 23(27) which belong to $\mathrm{IH}-1$ race group found to be grouped together in the same group with $100 \%$ similarity and collected in the same season (2009 season), except isolate number 23(27) which was collected in 2008 season. On the other hand, race group IG-1 which included isolates numbers 4(43), 27(62), 11(19), 16(68) and 24(78) placed into two groups with similarity ranged from $98 \%$ to $100 \%$ and collected from two different seasons (2008 and 2009 seasons). Isolates numbers 13(119), 18(114) and 25(122) which were identified as ID-13 were grouped together in the same group with $100 \%$ similarity and collected from

\section{CONCLUSION}

This research indicated that SSR markers would be a useful tool for the analysis of genetic diversity of $P$. grisea and would provide useful results for further studies including introduction of resistant cultivars.

\section{ACKNOWLEDGMENTS}

This study was supported by the Laboratory of the Molecular Biology Department at the Genetic Engineering and Biotechnology Research Institute, Minufiya University, Sadat City, Egypt. the same season (2010 season). Race group (II) which consists of five isolates; 3(13), 15(28), 20(88), 21(21) and 19(26) were paced into the same large group with different subgroups with similarity ranged from $70 \%$ to $80 \%$ and were collected through the same season (2008 season) except isolate number 20 (88) that was collected in 2009 season. Isolates numbers 22 (25), 9 (125), 29 (87), and 14 (121) which belong to race group IB were classified into different groups through the cluster.

The study showed that the isolates which were originating from the same host plant and from the same location belong to different groups (Table 2 and Figure 4). The clustering of these isolates was largely dependent on race (pathotype) background rather than locations and sources. High level of genetic diversity detected among Pyricularia grisea isolates reflects the ability of blast fungus to mutate and generate new physiological races. The investigation demonstrated the usefulness of simple sequence repeat technique in detecting genetic diversity in Pyricularia grisea fungus populations.

Ying et al. [2004] studied the genetic diversity of 105 isolates of $P$. grisea collected from the farms of China by using 7 SSR markers and declared that the similarity among the isolates was high and by cutting the cluster analysis diagram from the similarity point of 0.67 , they divided isolates into 6 groups. Chadha and Gopalakrishna [2005] studied the genetic diversity of this fungus which was collected from different parts of India and found that the genetic similarity among the isolates was high with ranges from 0.67 to 0.92 . They also studied 20 isolates of $P$. grisea divided into two groups and each group divided into two subgroups. Consolo et al. [2008] evaluated the genetic diversity of 161 isolates of $P$. grisea which were collected from the farms of Argentina and declared these isolates had a high similarity (more than $70 \%$ ) and were divided into five groups by the cluster analysis. Motlagh et al. [2015] studied the genetic diversity of 30 isolates $P$. grisea populations of Guilan province in Iran and they reported that these isolates had a high similarity. The results showed that the studied isolates were classified into 3 lineages by cutting off the dendrogram at 0.76 similar linkage level.

\section{REFERENCES}

Agrama, H., Tuinstra, M.R. (2003). Phylogenetic diversity and relationship among sorghum accessions using SSR and RAPD. African J. Biotechnol., 10, 334- 340.

Anderson, J.A.; Churchill, G.A.; Autrique, J.E.; Tanksley, S.D. and Sorrells, M.E. (1993). Optimizing parental selection for genetic linkage maps. Genome, 36, 1: 181-186.

Babujee, L., Gnanamanickam, S.S. (2000). Molecular tools for characterization of rice blast pathogen (Magnaporthe grisea) population and molecular marker-assisted breeding for disease resistance. Curr. Sci., 78(3), 248-257. 
Badawi, A. T.; M. A. Maximos and I. R. Aidy (2002). Rice improvement in Egypt during 85 years (1917- 2001). 1-24 pp. In: Rice in Egypt. Theresa Castello (ed.). Rice Research and Development Program, Ministry of Agriculture, Egypt.

Brondani, C., Garrido, L.R., Ferreira, M.E. (2000). Development of microsatellite markers for the genetic analysis of Magnaporthe grisea. Gen. Mol. Biol., 23(4), 753-762.

Chadha, S., Gopalakrishna, T. (2005). Genetic diversity of Indian isolates of rice blast pathogen (Magnaporthe grisea) using molecular markers. Curr. Sci., 88(9), 1466-1469.

Consolo, V.F., Cordo, C.A., Salerno, G.L. (2008). DNA fingerprint and pathotype diversity of Pyricularia oryzae populations from Argentina. Australas. Plant Pathol., 37, 357-364.

Gad, M.A., Ibrahim, N.A., Bora, T.C. (2013). Molecular biodiversity in phytopathogenic fungi, Pyricularia spp. J. Biol. Chem. Res., 30(1), 216-226.

Khodaparast, A.K., Sahragard, A. (2004). The rice diseases. University of Guilan publications.

Liu, L., Li, J., Su, Y., Wang, Y., Xie, Y., Zhu, Y. (2008). Polymorphism microsatellite sequence within $\mathrm{ABC}$ transporter genes in phytopathogenic Magnaporthe grisea, IFIP International Federation for Information Processing. Comp. Comp. Tech. Agricult., 258(1), 553-558.

McCouch, S. R.; L. Teytelman; Y. Xu; K. B. Lobos; K. Clare; M. Walton; B. Fu; R. Maghirang; Z. Li; Y. Xing; Q. Zhang; I. Kono; M. Yano; R. Fjellstorm; G. DeClerck; D. Schneider; S. Cartinhour; D. Ware and L. Stein (2002). Development and mapping of 2240 new SSR markers for rice (Oryza sativa L.). DNA Research 9: 199- 207.

Motallebi, P., Javan-Nikkhah, M., Okhovvat, M., Berdi Fotouhifar, K., Mosahebi, G.H. (2009). Differentiation of Magnaporthe species complex by rep-PCR genomic fingerprinting, Com-mun. Agric. Appl. Biol. Sci., 74(3), 821-829.

Motlagh, M.R.S., Habibi, F., Ebadi, A.A. (2015). Genetic and molecular characterization of population of Pyricularia oryzae from rice. Acta Sci. Pol. Hortorum Cultus, 14(5),83-97.
Murray, M. G. and W. F. Thomposon (1980). Rapid isolation of high molecular weight plant DNA. Nucleic Acid Research, 8:4321-3425.

Nei, M. and W. H. Lei (1979). Mathematical model for studying genetic variation in terms of restriction end nucleases. Proceedings of the National Academy of Sciences, USA. 76:5269-5273.

Ou, S.H. (1985). Rice diseases. Commonwealth Mycological Institute, 2nd.

Piotti, E., Rigano, M.M., Rodolfi, R., Castiglione, M., Picco, A.M., Sala, F. (2005). Genetic struc-ture of Pyricularia grisea, isolates from Italian paddy fields. J. Phytopathol., 153(2), 80-86.

Rohlf, J. (2000). Numerical taxonomy and multivarieties analysis system NTSYS.PC. version 2 Exeter software, New York.

Sehly, M. R., Z. H. Osman, and E. A. Salem (2002). Rice diseases. In: Rice in Egypt, pp 301.

Sehly, M. R., M. S. Nazim, and R. A. S. El-Shafey (2009). Host Rang of Pyricularia grisea And 10Year Development of New Rice Blast Races. J. Agric. Sci. Mansoura Univ., 34(4):3869-3882.

Silva, G.B., Prabhu, A.S., Filippi, M.C.C., Trindade, M.G., Araújo, L,G., Zambolim, L. (2009). Genetic and phenotypic diversity of Magnaporthe oryzae from leaves and panicles of rice in commercial fields in the State of Goiás, Brazil. Tropic. Plant Pathol., 34(2),77-86.

Vanaraj, P., Kandasamy, S., Ambalavanan, S., Ramalingam, R., Sabariyappan, R. (2013). Variability in Pyricularia oryzae from different rice growing regions of Tamil Nadu, India. Afr. J. Microbiol. Res., 7(26), 3379-3388.

Winter, P., Kahl, G. (1995). Molecular marker technologies for plant improvement. World J. Microbiol. Biotechnol., 11, 438-448.

Ying, S., Froun, J., Yue-Qiu, H., Kaya, C., Fang-Hua, X., Notteghem, J.L., Er-Ming, L., Tharreau, D. (2004). The perfect stage and SSR analysis of Magnaporthe grisea in Yanxi blast nursery. Chinese J. Rice Sci., 18(3), 262-268.

Zhou, H.F., Xie, Z.W., Ge, S. (2003). Microsatellite analysis of genetic diversity and population genetic structure of a wild rice (Oryza rufipogon Griff.) in China. Theor. Appl. Genet., 107(2), 332-339. 
التــوع الـوراثي في عثـائر فطر Pyricularia grisea المسبب لمـرض اللفحـة في الأرز باسـتخدام المعلمـات الجزيئية

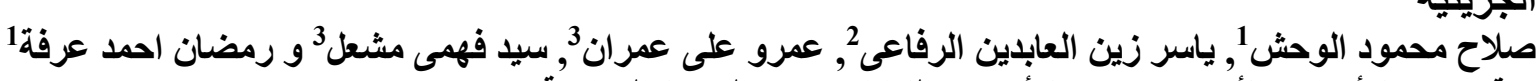

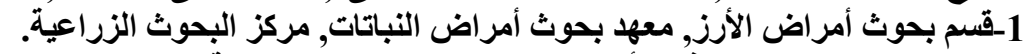

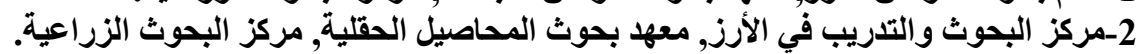
3ققم النبات الزراعى, كلية الزراعة, جامعة كفر الثيخ.

يعتبر فطر العyricularia grisea احد المسبيات المرضية الرئيسية التي تهدد محصول الأرز في مصر و والعالم. تم انتخاب

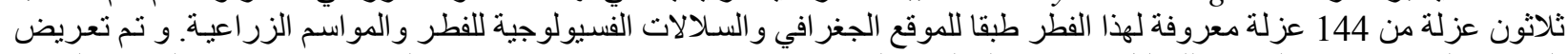

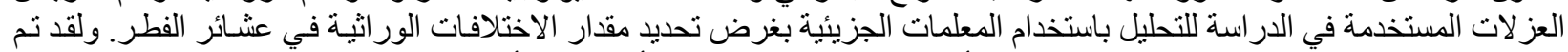

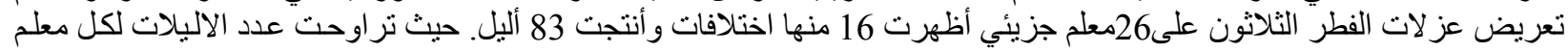

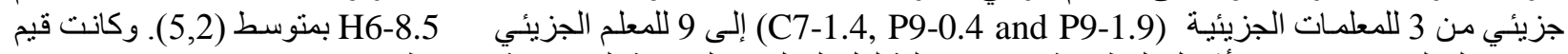

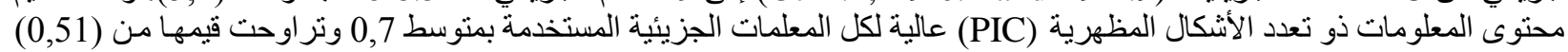

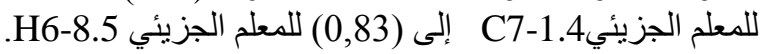

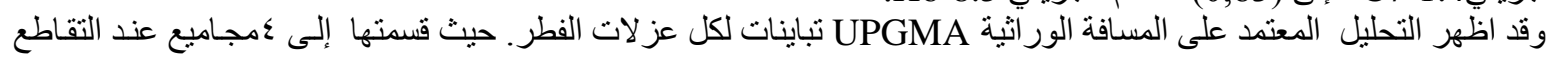

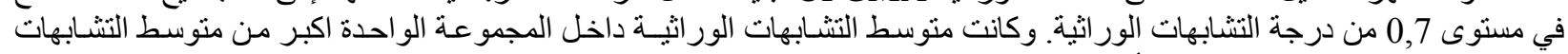

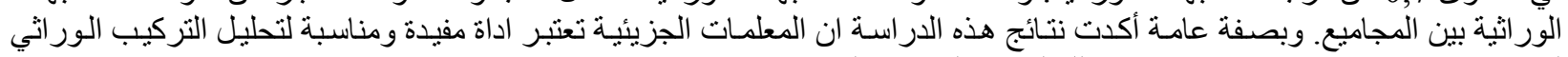
لعثائر فطر Pyricularia grisea وكنللك لتحديد التباينات الور اثثية بينها. 